\title{
BODY MASS OF LATE QUATERNARY MAMMALS
}

\author{
Ecological Archives E084-094
}

\author{
Felisa A. Smith, ${ }^{1}$ S. Kathleen Lyons, S. K. Morgan Ernest, Kate E. Jones, Dawn M. Kaufman, \\ Tamar Dayan, Pablo A. Marquet, James H. Brown, and John P. Haskell \\ ${ }^{1}$ Working Group on Body Size in Ecology and Paleoecology, National Center for Ecological Analysis and Synthesis \\ (NCEAS), 735 State Street, Suite 300, Santa Barbara, California 93101-5504
}

\begin{abstract}
The purpose of this data set was to compile body mass information for all mammals on Earth so that we could investigate the patterns of body mass seen across geographic and taxonomic space and evolutionary time. We were interested in the heritability of body size across taxonomic groups (How conserved is body mass within a genus, family, and order?), in the overall pattern of body mass across continents (Do the moments and other descriptive statistics remain the same across geographic space?), and over evolutionary time (How quickly did body mass patterns iterate on the patterns seen today? Were the Pleistocene extinctions size specific on each continent, and did these events coincide with the arrival of man?). These data are also part of a larger project that seeks to integrate body mass patterns across very diverse taxa (NCEAS Working Group on Body Size in Ecology and Paleoecology: linking pattern and process across space, time, and taxonomic scales). We began with the updated version of D. E. Wilson and D. M. Reeder's taxonomic list of all known Recent mammals of the world $(N=4629$ species) to which we added status, distribution, and body mass estimates compiled from the primary and secondary literature. Whenever possible, we used an average of male and female body mass, which was in turn averaged over multiple localities to arrive at our species body mass values. The sources are line referenced in the main data set, with the actual references appearing in a table within the metadata. Mammals have individual records for each continent they occur on. Note that our data set is more than an amalgamation of smaller compilations. Although we relied heavily on a data set for Chiroptera by K. E. Jones $(N=905)$, the CRC handbook of Mammalian Body Mass $(N=688)$, and a data set compiled for South America by P. Marquet $(N=505)$, these represent less than half the records in the current database. The remainder are derived from more than 150 other sources. Furthermore, we include a comprehensive late Pleistocene species assemblage for Africa, North and South America, and Australia (an additional 230 species). "Late Pleistocene" is defined as approximately $11 \mathrm{ka}$ for Africa, North and South America, and as $50 \mathrm{ka}$ for Australia, because these times predate anthropogenic impacts on mammalian fauna. Estimates contained within this data set represent a generalized species value, averaged across sexes and geographic space. Consequently, these data are not appropriate for asking population-level questions where the integration of body mass with specific environmental conditions is important. All extant orders of mammals are included, as well as several archaic groups $(N=4859$ species $)$. Because some species are found on more than one continent (particularly Chiroptera), there are 5731 entries. We have body masses for the following: Artiodactyla (280 records), Bibymalagasia (2 records), Carnivora (393 records), Cetacea (75 records), Chiroptera (1071 records), Dasyuromorphia (67 records), Dermoptera (3 records), Didelphimorphia (68 records), Diprotodontia (127 records), Hydracoidea (5 records), Insectivora (234 records), Lagomorpha (53 records), Litopterna (2 records), Macroscelidea (14 records), Microbiotheria (1 record), Monotremata (7 records), Notoryctemorphia (1 record), Notoungulata (5 records), Paucituberculata (5 records), Peramelemorphia (24 records), Perissodactyla (47 records), Pholidota (8 records), Primates (276 records), Proboscidea (14 records), Rodentia (1425 records), Scandentia (15 records), Sirenia (6 records), Tubulidentata (1 record), and Xenarthra (75 records).
\end{abstract}

Key words: body mass; extinct mammals; late Quaternary; macroecology; taxonomy.

Manuscript received 14 November 2002; revised 20 October 2003; accepted 21 October 2003. Corresponding Editor: W. K. Michener.

${ }^{1}$ Corresponding author: Department of Biology, University of New Mexico, Albuquerque, New Mexico 87131 USA, fasmith@unm.edu 